\title{
Nerve Growth Factor Modulates Synaptic Transmission between Sympathetic Neurons and Cardiac Myocytes
}

\author{
Sybil T. Lockhart, ${ }^{1}$ Gina G. Turrigiano, ${ }^{1,2}$ and Susan J. Birren ${ }^{1,2}$ \\ ${ }^{1}$ Department of Biology and 2Volen National Center for Complex Systems, Brandeis University, Waltham, Massachusetts \\ 02254-9110
}

Regulation of heart rate by the sympathetic nervous system involves the release of norepinephrine (NE) from nerve terminals onto heart tissue, resulting in an elevation in beat rate. Nerve growth factor (NGF) is a neurotrophin produced by the heart that supports the survival and differentiation of sympathetic neurons. Here we report that NGF also functions as a modulator of sympathetic synaptic transmission. We determined the effect of NGF on the strength of synaptic transmission in co-cultures of neonatal rat cardiac myocytes and sympathetic neurons from the superior cervical ganglion (SCG). Synaptic transmission was assayed functionally, as an increase in the beat rate of a cardiac myocyte during stimulation of a connected neuron. Application of NGF produced a pronounced, reversible enhancement of synaptic strength. We found that TrkA, the re- ceptor tyrosine kinase that mediates many NGF responses, is expressed primarily by neurons in these cultures, suggesting a presynaptic mechanism for the effects of NGF. A presynaptic model is further supported by the finding that NGF did not alter the response of myocytes to application of NE. In addition to the acute modulatory effects of NGF, we found that the concentration of NGF in the growth medium affects the level of synaptic transmission in cultures of sympathetic neurons and cardiac myocytes. These results indicate that in addition to its role as a survival factor, NGF plays both acute and long-term roles in the regulation of developing sympathetic synapses in the cardiac system.

Key words: synaptic transmission; modulation; sympathetic; TrkA; cardiac; NGF
The maintenance of cardiac homeostasis is dependent on the balance of neural inputs to the heart from the sympathetic and parasympathetic nervous systems (Cannon, 1929). Sympathetic stimulation of heart beat rate is mediated by the release of norepinephrine (NE) from sympathetic nerve terminals in the heart (Armour and Ardell, 1994). Although the role of the sympathetic nervous system in regulating heart rate is well known, little is known about the process by which sympathetic neurons form stable, active synapses as they innervate the myocardial tissue, or the factors that modulate synaptic activity between these neurons and their target cells.

One candidate for such a modulator is nerve growth factor (NGF) (Levi-Montalcini and Angeletti, 1968). In the periphery, NGF influences neuronal survival and differentiation in the developing sympathetic and sensory nervous systems (for review, see Thoenen and Barde, 1980; Eide et al., 1993). NGF is expressed in the heart and in other sympathetic targets around the time of initial innervation (Davies et al., 1987; Korsching and Thoenen, 1988; Clegg et al., 1989). During this developmental period, TrkA, a receptor tyrosine kinase that mediates NGF function (Kaplan et al., 1991; Klein et al., 1991), is expressed on the surface of sympathetic neurons (Verdi and Anderson, 1994;

Received June 27, 1997; revised Sept. 24, 1997; accepted Oct. 6, 1997.

S.T.L. is supported by National Institutes of Health Grant NS07292. S.J.B. is a Pew Scholar. This work was supported by a grant from the Whitehall Foundation and a Beginning Grant-in-Aid from the Massachusetts Affiliate of the American Heart Association to S.J.B., and National Science Foundation Grant IBN-9421233 to G.G.T. We thank Dr. Louis Reichardt for the rtrkA antibody, Jessica Pisano for helpful discussions, Trina Sarafi for immunocytochemistry advice, Meredith Fisher for technical support, and Drs. Eve Marder and Melissa Coleman for critical reading of this manuscript.

Correspondence should be addressed to Dr. Susan J. Birren, Department of Biology MS 008, Brandeis University, 415 South Street, Waltham, MA 02154-9110. Copyright (C) 1997 Society for Neuroscience $0270-6474 / 97 / 179573-10 \$ 05.00 / 0$
Wyatt and Davies, 1995). After the initial developmental upregulation of TrkA, expression of p75, the low-affinity neurotrophin receptor (Radeke et al., 1987; Johnson et al., 1988), also increases (Verdi and Anderson, 1994; Wyatt and Davies, 1995). The level of NGF regulates the number of surviving sympathetic neurons (Levi-Montalcini and Booker, 1960; Albers et al., 1994; Hassankhani et al., 1995), their dendritic arborization (Purves et al., 1988; Snider, 1988), and the level of target innervation (Korsching and Thoenen, 1983; Shelton and Reichardt, 1984).

NGF in the sympathetic nervous system has been considered to function as a target-derived survival factor, supplied in limiting quantities by target organs such as the heart, to regulate the final number of neurons and density of innervation (Cowan et al., 1984; Purves, 1988). However, recent evidence suggests that members of the neurotrophin family can also modulate synaptic activity. This has been demonstrated in rat cortical neurons (Kim et al., 1994; Rutherford et al., 1997; Takei et al., 1997), in rat hippocampus (Knipper et al., 1994; Kang and Schuman, 1995; Levine et al., 1995; Figurov et al., 1996; Tanaka et al., 1997), and at Xenopus neuromuscular synapses (Lohof et al., 1993; Wang et al., 1995). At some synapses the effects of neurotrophins on synaptic function are acute and reversible, as shown in the cortex and at Xenopus neuromuscular synapses (Lohof et al., 1993; Kim et al., 1994). Neurotrophins also mediate long-term changes in synaptic connections in the hippocampus (Kang and Schuman, 1995) and in neocortical neurons (Rutherford et al., 1997). One neurotrophin, brain-derived neurotrophic factor, influences longterm potentiation (LTP) in mouse and rat hippocampus (Korte et al., 1995; Figurov et al., 1996). These studies indicate that neurotrophins are important modulators of neuronal plasticity at synapses formed by CNS neurons.

The role of neurotrophins in modulating synaptic transmission 
at autonomic synapses is not clear. Synapses formed between sympathetic neurons and their peripheral targets have distinct structural and functional properties. Compared with neurotrophinmodulated synapses between CNS neurons and their targets, noradrenergic sympathetic synapses onto target cells lack synaptic specializations (Landis, 1976; Nobin et al., 1979; Kobayashi et al., 1984), have variable and sometimes large distances between the pre- and postsynaptic cells (Landis, 1976; Kitajiri et al., 1993), and trigger slow, second messenger-mediated postsynaptic responses (Hartzell, 1981). NGF is known to act on sympathetic neurons, promoting their survival and differentiation (Chun and Patterson, 1977; Levi-Montalcini, 1987) and enhancing neuritic growth and target innervation (Campenot, 1982b; Korsching and Thoenen, 1983; Shelton and Reichardt, 1984; Snider, 1988). Here, we demonstrate that NGF can also potentiate synaptic transmission between sympathetic neurons and cardiac myocytes in vitro. Modulation of these sympathetic synapses by NGF is acute and reversible, and we present evidence that synaptic potentiation works through a presynaptic mechanism. In addition to acute modulatory effects on synaptic efficacy, we demonstrate that NGF produces a long-term enhancement of synaptic transmission in cultures of sympathetic neurons and cardiac myocytes.

\section{MATERIALS AND METHODS}

Isolation and culture of primary neonatal sympathetic neurons and ventricular myocytes. Modulation of synaptic activity by NGF was investigated using a sympathetic neuron-cardiac myocyte co-culture system. Experiments were performed on young mass cultures of neonatal sympathetic neurons and cardiac myocytes (Conforti et al., 1991) that were cultured under a modification of the conditions described by Furshpan and coworkers (Furshpan et al., 1976, 1986). Cardiac myocytes were isolated from neonatal Simonson White rat pups (Simonson Labs, Gilroy, CA). Rat pups were decapitated, and the posterior half of the cardiac ventricles were dissected (Conforti et al., 1991) and incubated twice for $12 \mathrm{~min}$ at $37^{\circ} \mathrm{C}$ in $1.5 \mathrm{mg} / \mathrm{ml}$ collagenase (Type I; Worthington Biochemical, Freehold, NJ), followed by a $32 \mathrm{~min}$ incubation in $1.5 \mathrm{mg} / \mathrm{ml}$ collagenase plus $1 \mathrm{mg} / \mathrm{ml}$ elastase (Type III; Sigma, St. Louis, MO) in Minimum Essential Medium with Earl's salts and 25 mM HEPES buffer (S-MEM; Life Technologies, Gaithersburg, MD). After this incubation, myocytes were rinsed three times in culture medium (MAH food; see below), triturated using a heat-polished Pasteur pipette, strained through Nitex Nylon mesh (Tetko, Lancaster, NY), and plated onto $35 \mathrm{~mm}$ glassbottomed culture dishes (MatTek, Ashland, MA) coated with $50 \mu \mathrm{g} / \mathrm{ml}$ rat tail collagen (Type I; Collaborative Biomedical Products/Becton Dickinson Labware, Bedford MA).

The superior cervical ganglia (SCG) were dissected, incubated for $1 \mathrm{hr}$ at $37^{\circ} \mathrm{C}$ in $1.5 \mathrm{mg} / \mathrm{ml}$ collagenase and $5 \mathrm{mg} / \mathrm{ml}$ dispase (Life Technologies), triturated, and then preplated on tissue culture plastic to permit the attachment of non-neuronal cells. After $2.5 \mathrm{hr}$, the dish was knocked sharply and rinsed; most of the more adherent Schwann cells and fibroblasts remained on the dish, whereas the neurons were rinsed into a separate tube, counted, and plated together with the myocytes. Most dishes were plated with $\sim 75,000$ myocytes and 15,000 neurons. In some experiments, myocytes were plated at lower densities $(20,000-50,000)$ or cultured for 1 week before the addition of neurons. The cells were cultured in $2 \times \mathrm{MAH}$ food, consisting of $\mathrm{L}_{15 \mathrm{CO}_{2}}$ (Hawrot and Patterson, 1979) plus $10 \%$ fetal bovine serum, $6 \mu \mathrm{g} / \mathrm{ml}$ dextrose, $2 \mathrm{~mm}$ glutamine (Whittiker), $100 \mathrm{U} / \mathrm{ml}$ penicillin, $100 \mu \mathrm{g} / \mathrm{ml}$ streptomycin (Life Technologies), $1 \quad \mu \mathrm{g} / \mathrm{ml} \quad 6,7, \quad$ dimethyl-5,6,7,8-tetrahydropterine (DMPH4, Calbiochem, La Jolla, CA), $5 \mu \mathrm{g} / \mathrm{ml}$ glutathione (Sigma), and $100 \mu \mathrm{g} / \mathrm{ml} \mathrm{L}$-ascorbic acid (Sigma); 5 or $50 \mathrm{ng} / \mathrm{ml}$ of $2.5 \mathrm{~S}$ NGF from mouse submaxillary gland (Upstate Biotech, Lake Placid, NY) was added to support neuronal survival in cultures used for potentiation experiments, and $0-50 \mathrm{ng} / \mathrm{ml}$ of NGF was added to cultures to examine the dose-dependence of survival in NGF.

In experiments in which the cells were cultured for $>2 \mathrm{~d}, 1 \mu \mathrm{M}$ cytosine arabinofuranoside (AraC; Sigma) was added to the dishes to stop cell division. Cultures were grown for $\sim 36 \mathrm{hr}$ before use to allow synaptic connections to form and myocytes to begin beating. Survival experiments were performed in 24-well tissue culture dishes, in duplicate, at a com- parable cell density to that in physiology experiments. NGF was added 2 hr after plating, to rule out possible effects of NGF on plating efficiency. Cells were counted 2-3 d after plating.

Electrophysiology and imaging of sympathetic neurons and myocytes. Cultures were visualized using an inverted Nikon Diaphot microscope with differential interference contrast and fluorescence optics. A CCD camera was used to capture images onto a 7100 AV Power Macintosh. Whole-cell recordings were obtained using 3-4 $\mathrm{m} \Omega$ patch electrodes with 2 - $\mu \mathrm{m}$-diameter tips made on a Flaming-Brown micropipette puller (model P-87; Sutter Instruments). The intracellular solution contained $130 \mathrm{~mm}$ $\mathrm{KMeSO}_{4}, 10 \mathrm{~mm} \mathrm{KCl}, 10 \mathrm{~mm}$ potassium-HEPES, pH 7.4, $2 \mathrm{~mm} \mathrm{MgSO}_{4}$, $0.5 \mathrm{~mm}$ EGTA (Sigma), and $3 \mathrm{~mm}$ ATP (Sigma). Cultures were perfused continuously with artificial cerebral spinal fluid (ACSF; $126 \mathrm{~mm} \mathrm{NaCl}, 3$ $\mathrm{mm} \mathrm{KCl}, 2 \mathrm{~mm} \mathrm{MgSO}_{4}, 1 \mathrm{~mm} \mathrm{NaH} \mathrm{PO}_{4}, 25 \mathrm{~mm} \mathrm{NaHCO}, 11 \mathrm{~mm}$ dextrose, and $2 \mathrm{~mm} \mathrm{CaCl}_{2}$ ), bubbled with $5 \% \mathrm{CO}_{2}, 95 \% \mathrm{O}_{2}$. We routinely achieved 4-6 G $\Omega$ seals under these conditions.

Signals were amplified and current injection was controlled through an Axoclamp 2B (Axon Instruments, Foster City, CA). Evoked synaptic activity was studied by injecting $200 \mathrm{msec}$ pulses of current into a presynaptic sympathetic neuron, thereby eliciting single action potentials at a frequency of $2.5 \mathrm{~Hz}$ for $3 \mathrm{~min}$, and manually counting the number of spontaneous contractions per minute (beat rate) of connected myocytes. The electrophysiology rig was configured so that a single investigator could monitor both the evoked activity and the myocyte beat rate, although in some experiments these activities were monitored independently by two investigators. For each condition, the same number of action potentials was elicited at the same frequency during each $3 \mathrm{~min}$ stimulation. A neuron-myocyte pair was considered to be connected if the 3 min neuronal stimulation in control solution induced an increase in myocyte beat rate of four beats per min or greater. This criterion was based on the variability in the baseline myocyte beat rate. We calculated the baseline fluctuation in myocyte beat rate for each cell as the absolute mean deviation $(\Sigma|x-m|) / n$, where $x$ is the beat rate of the myocyte for each minute of baseline, $m$ is its average beat rate over the entire baseline, and $n$ is the number of minutes of baseline. Minute-to-minute fluctuations in the baseline myocyte beat rate approached a normal distribution. The average absolute mean deviation was 1.5 beats $/ \mathrm{min}$, \pm 0.95 beats $/ \mathrm{min}$ (SD). Thus, $99 \%$ of changes of four beats $/ \mathrm{min}$ or greater (2.6 SDs) could be considered to be nonrandom.

NGF was applied at $10-50 \mathrm{ng} / \mathrm{ml}$ in ACSF. K252a (Kamiya Biomedical, Thousand Oaks, CA) was dissolved in dimethyl sulfoxide (DMSO; Sigma) at a concentration of $0.02 \mathrm{~mm}$ to make a stock solution that was aliquotted and stored at $-20^{\circ} \mathrm{C}$, and diluted into ACSF at a final concentration of $200 \mathrm{nM}$. In some experiments, an equal amount $(0.01 \%)$ of DMSO was added to controls; it had no effect on synaptic transmission. Solutions were perfused into the bath at a rate of $0.3-0.6 \mathrm{ml} / \mathrm{min}$. Analysis of dye exchange in these dishes indicated complete exchange within 3-6 min. In every modulation experiment, the growth medium was initially washed from the dish by perfusing with control medium for at least $30 \mathrm{~min}$. For each new bath condition, cells were perfused for a minimum of $10 \mathrm{~min}$, ensuring complete exchange of the bath solution. For picospritzer experiments, $10^{-5} \mathrm{M}$ NE (Research Biochemicals International, Natick, MA) was dissolved into ACSF adjusted to pH 7.4 with HEPES buffer. The NE solution was puffed onto myocytes for 75 msec at 20 psi using a Picospritzer (General Valve Picospritzer II) and pipettes with a tip diameter of $\sim 1 \mu \mathrm{m}$.

Isolation of RNA and RT-PCR. RNA was isolated from $\sim 15,000 \mathrm{SCG}$ neurons and/or 75,000 myocytes using a guanidinium/water-saturated phenol method as described (Chomszynski and Sacchi, 1987). Reverse transcriptase was used to generate first-strand cDNA from the RNA. This cDNA was amplified with Taq polymerase and oligonucleotide primers specific for trkA (Verdi et al., 1994b): upstream, 5'-ATG AGA CCA GCT TCA TC-3'; downstream, 5'-CAT TCT CAA GTG GGA GC-3'.

Immunocytochemistry. Sympathetic neuron-cardiac myocyte cocultures were grown in glass-bottomed culture dishes. After $3 \mathrm{~d}$ of culture we fixed the cells in $3.7 \%$ formaldehyde plus $5 \%$ sucrose in PBS. Cells were pre-blocked in PBS plus $10 \%$ normal goat serum and $0.1 \%$ Nonidet P-40 (Sigma) for $30 \mathrm{~min}$ at room temperature and then incubated in polyclonal rabbit anti-TrkA primary antibody (rtrkA; a generous gift of Dr. Louis Reichardt) at 1:1000 in pre-block overnight at $4^{\circ} \mathrm{C}$. The secondary antibody was goat anti-rabbit IgG-rhodamine, which was used at 1:200 in PBS plus 1\% normal goat serum. Cells were incubated in secondary antibody for $40 \mathrm{~min}$ at room temperature.

Statistical notation. All values are reported and graphed as mean \pm SEM for the number of cells indicated, unless noted otherwise. $p$ values 


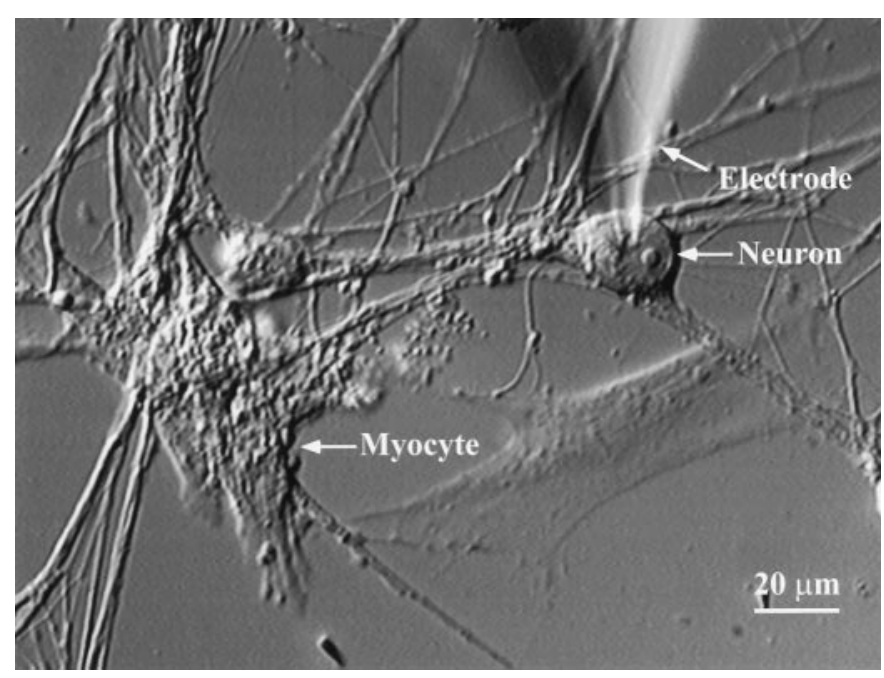

Figure 1. Sympathetic neuron-myocyte co-culture. In 3-d-old cocultures of neonatal rat cardiac myocytes and sympathetic neurons isolated from the superior cervical ganglion, neurons extend processes that form visible connections with spontaneously beating myocytes. Functional assays of synaptic transmission were performed by obtaining a whole-cell recording on the neuron, stimulating the neuron to fire action potentials, and measuring the change in beat rate of the connected myocyte.

are from paired Student's $t$ tests unless noted otherwise; $n=$ number of different cells.

\section{RESULTS}

\section{Functional assay for synaptic connections between sympathetic neurons and cardiac myocytes}

Co-cultures of sympathetic neurons and cardiac myocytes were prepared from neonatal rat pups. The neurons in these cultures elaborated extensive neuritic networks over the flat cells (Fig. 1) ( $3 \mathrm{~d}$ in culture). Flat cells in the cultures included cardiac myocytes and fibroblast-like cells. Under these culture conditions we observed spontaneous beating of some myocytes. Within $36 \mathrm{hr}$ of plating, the neurons established functional synapses onto the co-cultured cardiac myocytes.

As a functional assay for a synaptic connection, we obtained a whole-cell recording from a neuron visibly connected to a beating myocyte and stimulated the neuron with depolarizing current pulses to elicit action potentials at $2.5 \mathrm{~Hz}$. We measured the average number of myocyte beats per minute for a $3 \mathrm{~min}$ baseline $(B)$ before stimulation and again during a $3 \mathrm{~min}$ stimulation of the neuron $(S)$. The average spontaneous beat rate of myocytes was 22 beats/min (range, 2-62 beats/min). The average fluctuation in the baseline myocyte beat rate was 1.5 beats $/ \mathrm{min}$. If neuronal stimulation resulted in an increase in myocyte beat rate (defined as $S-B$ ) of four beats/min or greater, the neuronmyocyte pair was considered to be synaptically connected (see Materials and Methods). Using this criterion, $32 \%$ of tested pairs of cells were connected in control conditions. The average increase in myocyte beat rate during stimulation of a connected neuron for all cells tested in control conditions was $7.5 \pm 0.53$ beats/min. In these cultures, we observed very little spontaneous activity in the sympathetic neurons, as measured by the incidence of spontaneous neuronal action potentials. The spontaneous beat rate was therefore primarily a result of intrinsic properties of the myocytes.

\section{Potentiation of sympathetic neuron-myocyte synapses by NGF}

We tested the effects of NGF on synaptic transmission by comparing the increase in myocyte beat rate during neuronal stimulation in the absence and presence of NGF. After complete washout of the NGF-containing growth medium, we obtained a connected neuron-myocyte pair in control solution (ACSF; see Materials and Methods), as described above. The dish was then superfused for $10 \mathrm{~min}$ or longer with $50 \mathrm{ng} / \mathrm{ml} \mathrm{NGF}$, and the increase in myocyte beat rate was again measured during neuronal stimulation. Data from a single cell are shown in Figure $2 A$. In NGF, neuronal stimulation led to a dramatic increase in the response of the connected myocyte. This elevated myocyte beat rate had a rapid onset, usually appearing in the first minute of neuronal stimulation. In all experiments that included a washout of NGF, the response was rapidly and fully reversible; after a $10-15$ min washout, the response of myocytes to neuronal stimulation returned to approximately the level observed before the addition of NGF. After washout of NGF, the baseline myocyte beat rate was sometimes higher and sometimes lower than before NGF treatment (data not shown).

On average, the increase in beat rate in response to neuronal stimulation was nearly twice as large in $50 \mathrm{ng} / \mathrm{ml}$ NGF than in control solution (Fig. 2B). In this set of experiments, neuronal stimulation produced an average increase of $6.3 \pm 0.3$ myocyte beats $/ \mathrm{min}$ in control solution and $11.2 \pm 0.3$ beats $/ \mathrm{min}$ in $50 \mathrm{ng} / \mathrm{ml}$ NGF (NGF significantly different from control; $p<0.002 ; n=$ $15)$. We examined separately the NGF-mediated synaptic potentiation in cultures that had been grown at either 5 or $50 \mathrm{ng} / \mathrm{ml}$ NGF. We found no difference in the level of potentiation produced by acute application of $50 \mathrm{ng} / \mathrm{ml} \mathrm{NGF}$ after washout of the growth medium. We therefore combined the data from the two different growth conditions in Figure $2 B$. The increase in synaptic transmission in the presence of NGF was dependent on the concentration of NGF that was applied. NGF at $10 \mathrm{ng} / \mathrm{ml}$ did not potentiate the response of myocytes to neuronal stimulation (Fig. $2 B$ ) (average increase $6.58 \pm 0.88$ beats/min in control solution, and $6.15 \pm 0.70$ in $10 \mathrm{ng} / \mathrm{ml} \mathrm{NGF;} p<0.74 ; n=7)$.

NGF did not significantly alter the resting potential or input resistance of sympathetic neurons. Average resting potential was $-56.0 \pm 2.0 \mathrm{mV}$ in control solution and $-56.5 \pm 3.3 \mathrm{mV}$ in NGF; average input resistance was $400 \pm 27 \mathrm{M} \Omega$ in control solution and $433 \pm 56 \mathrm{M} \Omega$ in NGF.

\section{Sympathetic neuron survival requires lower doses of NGF than synaptic modulation}

Our observation that sympathetic synapses are potentiated by 50 but not $10 \mathrm{ng} / \mathrm{ml}$ NGF led us to investigate the concentration of NGF required to support neuronal survival under conditions of sympathetic neuron-cardiac myocyte co-culture. We tested neuronal survival at $0,0.5,5.0$, and $50 \mathrm{ng} / \mathrm{ml}$ of NGF. Similar to previous studies of rat sympathetic neurons cultured alone (Chun and Patterson, 1977; Hefti et al., 1982), we found that $5 \mathrm{ng} / \mathrm{ml}$ NGF was saturating for the survival of sympathetic neurons cultured in the presence or absence of cardiac myocytes (Fig. 3). This result indicates that the effective dose of NGF is lower for a survival response than for synaptic modulation in our cultures.

\section{TrkA is expressed predominantly on neurons in sympathetic neuron-cardiac myocyte co-cultures}

We next examined the question of whether NGF acts on the presynaptic neuron to increase synaptic transmission or through 


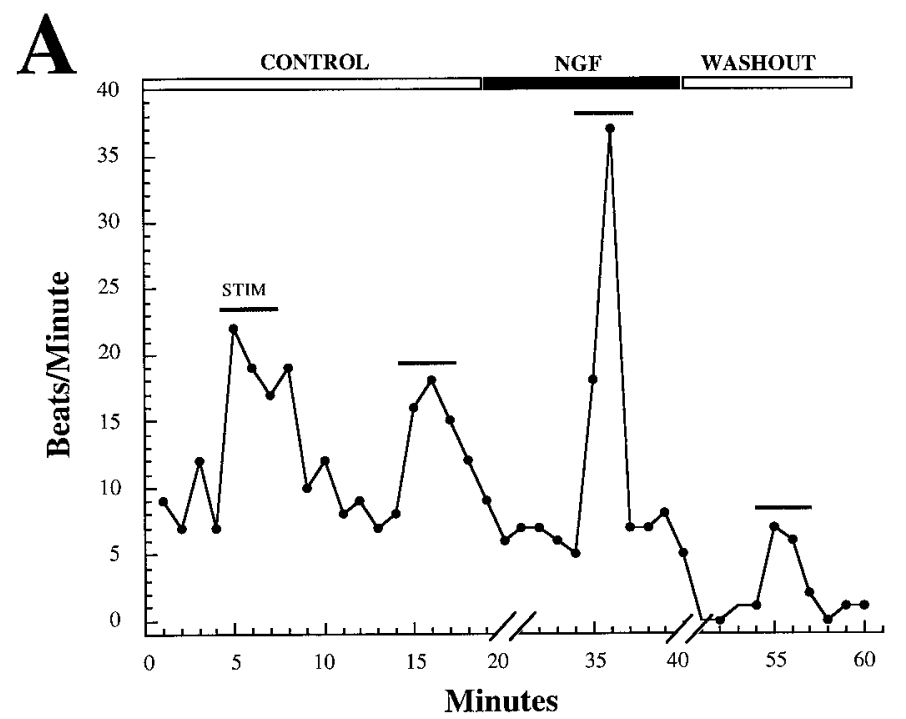

B

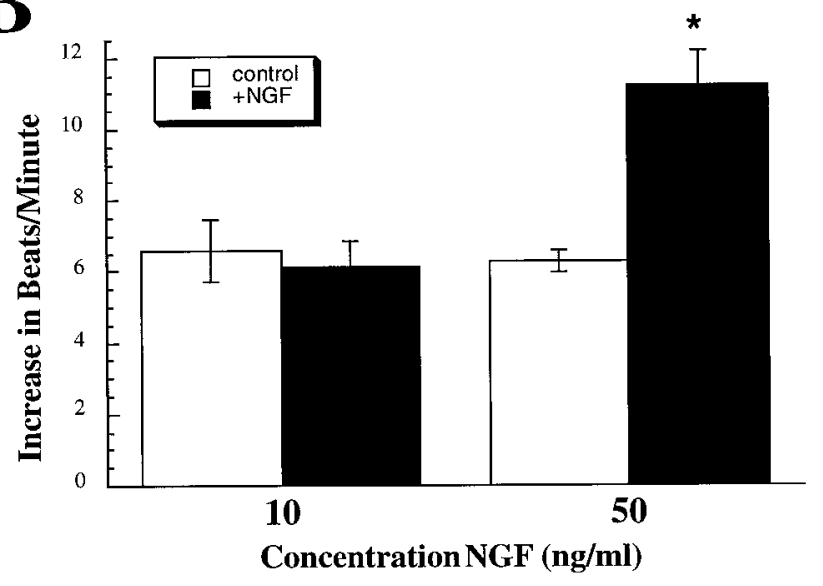

Figure 2. NGF modulates synaptic transmission between sympathetic neurons and beating myocytes. $A$, NGF reversibly potentiates myocyte response to stimulation of a connected neuron. A whole-cell recording was obtained from a neuron visibly connected to a beating myocyte. The neuron was stimulated at $2.5 \mathrm{~Hz}$ for a $3 \mathrm{~min}$ period (STIM; thin black bars), leading to a small increase in myocyte beat rate under control conditions. After superfusion of $50 \mathrm{ng} / \mathrm{ml}$ NGF into the bath solution (10 min) (the break in the timeline indicates that myocyte beat rate was not counted during this perfusion period), the myocyte response to neuronal stimulation was more than doubled. The response to stimulation returned to control levels after washout of the NGF $(10 \mathrm{~min}) . B$, Magnitude and concentration dependence of synaptic potentiation in NGF. The average myocyte beat rate was measured for a 3 min baseline period before neuronal stimulation and again during the 3 min stimulation. Open bars show the stimulation-evoked elevation in beat rate under control conditions. NGF $(10$ or $50 \mathrm{ng} / \mathrm{ml})$ was then superfused into the bath, and another 3 min baseline was counted. The neuron was stimulated, and the myocyte beat rate was counted for an additional 3 min period. The black bars show the stimulus-induced elevation in myocyte beat rate in the presence of NGF. $50 \mathrm{ng} / \mathrm{ml} \mathrm{NGF}$ : significantly different from control, $p<$ 0.002 , paired Student's $t$ test, $n=15 ; 10 \mathrm{ng} / \mathrm{ml}$ NGF: not significantly different from control, $p<0.74, n=7$; error bars represent SEM.

receptors on the myocytes to alter the postsynaptic response to transmitter release. TrkA is a receptor tyrosine kinase that mediates most of the known biological effects of NGF (Eide et al., 1993). We therefore examined the expression of trkA mRNA in sympathetic neurons, cardiac myocytes, and neuron-myocyte co-

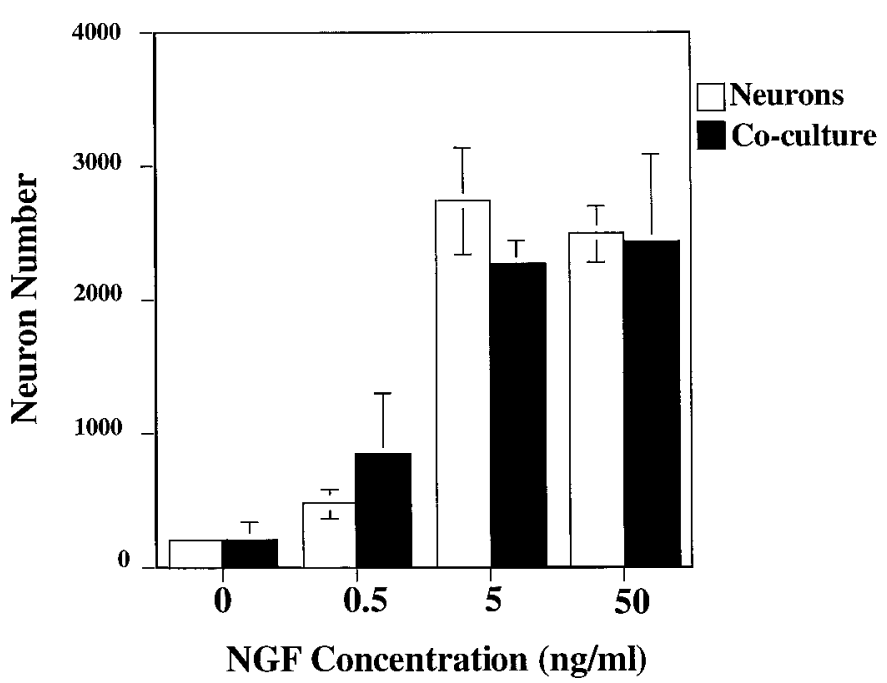

Figure 3. Dose dependence of neuronal survival in NGF. Duplicate wells containing neurons either alone (open bars) or in co-cultures with myocytes (black bars) were grown at varying concentrations of NGF. After $63 \mathrm{hr}$, a strip of neurons was counted across the tissue culture well for each condition. The average number of neurons remaining in the well was computed and plotted as a function of NGF concentration. In three independent experiments, $5 \mathrm{ng} / \mathrm{ml} \mathrm{NGF}$ was sufficient to support neuronal survival. Error bars represent SDs.

cultures using RT-PCR (Fig. 4A). TrkA mRNA was present in both neuronal and co-cultures at levels that were readily detectable by RT-PCR followed by ethidium bromide staining of PCR products. In contrast, trkA mRNA expression was barely detectable in myocytes. The identity of the trkA bands was confirmed by Southern analysis (data not shown).

We also examined the expression of TrkA protein in sympathetic neuron-myocyte co-cultures using immunocytochemistry (Fig. 4B). TrkA was highly expressed in sympathetic neurons grown in co-culture with cardiac myocytes. In contrast, antibodies to TrkA only lightly stained cardiac myocytes, indicating a low level of expression. Thus, at both the protein and RNA level, TrkA is more highly expressed in sympathetic neurons than in cardiac myocytes.

\section{NGF does not alter postsynaptic responses to neurotransmitter}

Although the expression pattern of TrkA on sympathetic neurons and cardiac myocytes suggests a presynaptic mechanism for synaptic potentiation by NGF, we could not rule out the possibility that low levels of TrkA on the myocytes were responsible for the observed effects. We therefore tested whether NGF altered the postsynaptic response to neurotransmitter by directly applying $\mathrm{NE}$ onto myocytes in the presence and absence of NGF. If NGF acts presynaptically to potentiate synaptic transmission, we would predict that NGF would not potentiate the effects of NE application. If, however, NGF enhances the postsynaptic response to $\mathrm{NE}$, we would expect $\mathrm{NE}$ application to result in a higher rate of beating in the presence of NGF. We used a picospritzer to apply $\mathrm{NE}$ to spontaneously beating myocytes in the presence and absence of NGF. Myocytes in co-cultures were used for this experiment, to ensure that all conditions were identical between the different sets of experiments. NE was applied by guiding a glass electrode with a tip diameter of $1 \mu \mathrm{m}$ to a beating myocyte in control solution and puffing on $10^{-5} \mathrm{M} \mathrm{NE}$ at 20 psi for $75 \mathrm{msec}$. NGF (50 ng/ml) was then superfused into the dish, and NE was 

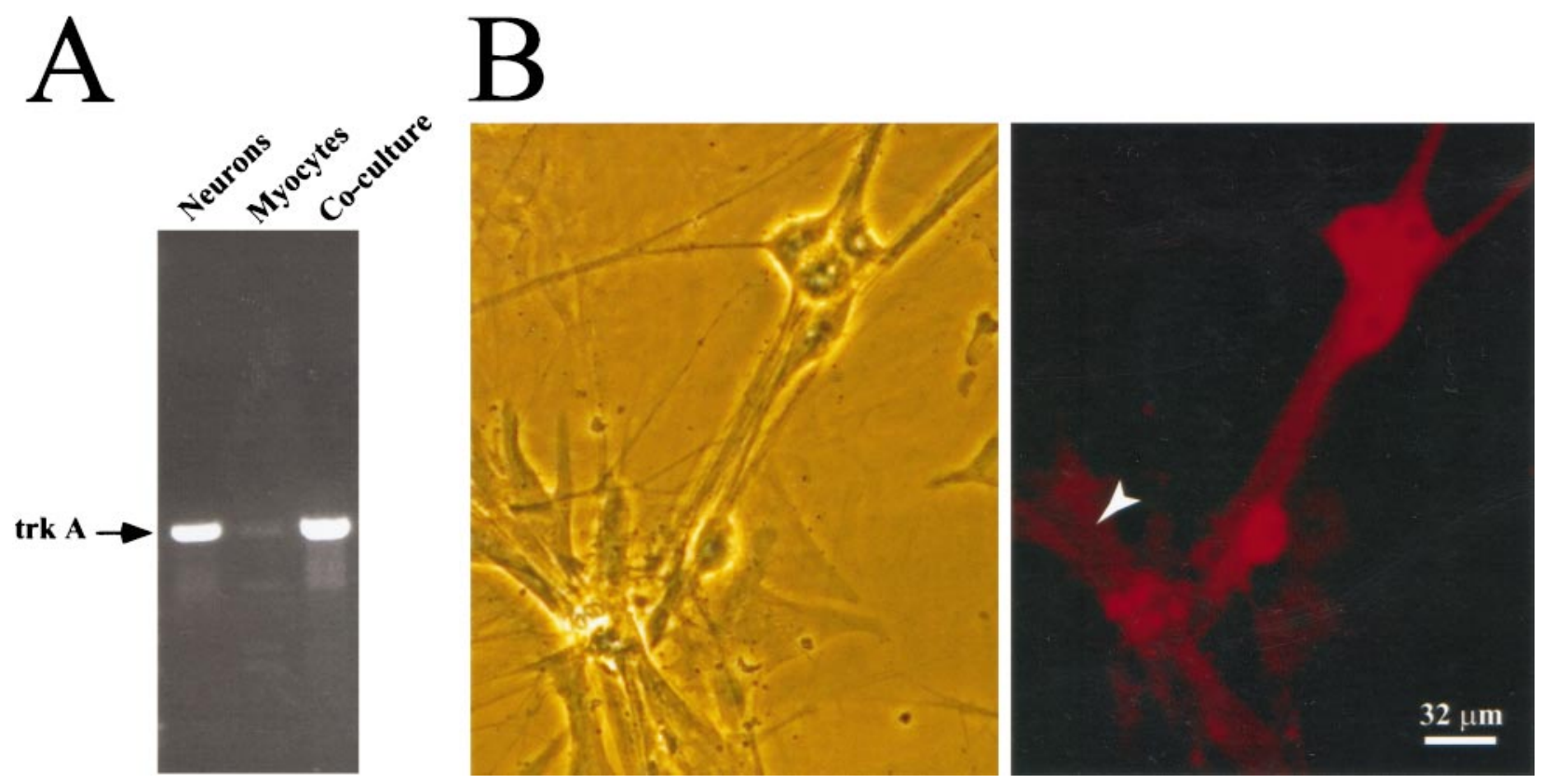

Figure 4. Expression of TrkA in neuron-myocyte co-cultures. $A$, trkA mRNA in sympathetic neurons, cardiac myocytes, and neuron-myocyte co-cultures by RT-PCR. mRNA extracted from 3-d-old cultures was reverse-transcribed and PCR-amplified using primers specific for trkA. The resulting PCR products were analyzed by agarose gel electrophoresis and ethidium bromide staining. $B$, Expression of TrkA protein in sympathetic neurons and cardiac myocytes grown in co-culture was analyzed by immunocytochemistry. Neurons and myocytes were grown for $3 \mathrm{~d}$ in co-culture, fixed, and stained with the rtrkA antibody. Left panel, Phase-contrast photograph of neuron-myocyte co-culture after fixation. Right panel, TrkA staining. The arrow indicates a myocyte.

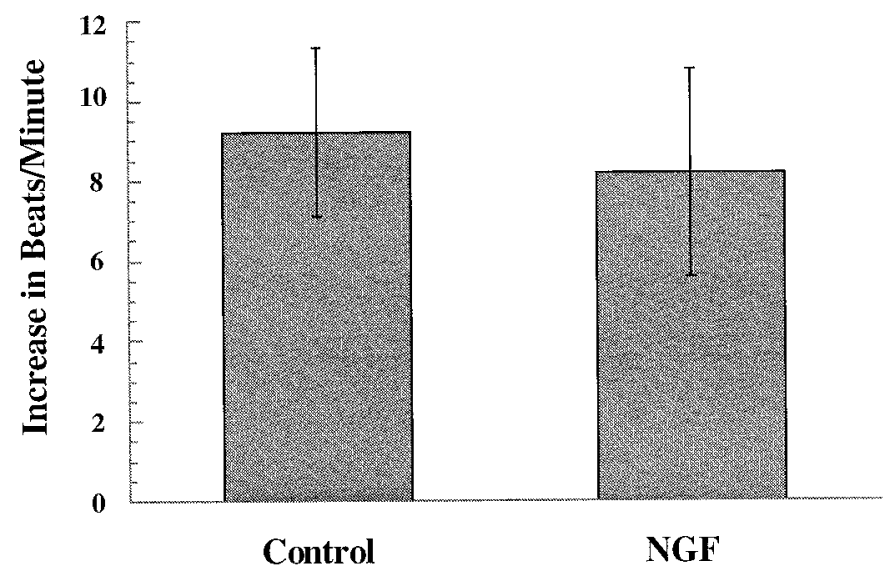

Figure 5. Effect of NGF on the NE-induced change in myocyte beat rate. A glass electrode with a tip diameter of $1 \mu \mathrm{m}$ was micromanipulated close to a beating myocyte in a neuron-myocyte co-culture. A baseline myocyte beat rate was counted, and then a picospritzer was used to puff $10^{-5} \mathrm{M} \mathrm{NE}$ at 20 psi for $75 \mathrm{msec}$. The myocyte beat rate was counted for 3 min after delivery of the $\mathrm{NE}$, and the change in beat rate was calculated (Control). NGF $(50 \mathrm{ng} / \mathrm{ml})$ was superfused into the dish, another baseline was counted for the same myocyte, and again $\mathrm{NE}$ was puffed onto the myocyte. The increase in beat rate was calculated for NE application in the presence of NGF. NGF not different from control, $p<0.7$; paired Student's $t$ test; $n=13$.

again puffed onto the myocyte. The myocyte beat rate was measured before and during each NE application, and the change in beat rate was calculated for each application (Fig. 5). After the first application of $\mathrm{NE}$, the electrode was removed from the dish to prevent any desensitization caused by leakage from the pipette. After addition of NGF, the electrode was repositioned in the same spot for the second NE application. We found no significant difference in the average response of a myocyte to NE in NGF compared with control solution (average increase in beats/min was $9.2 \pm 2.1$ in NGF and $8.2 \pm 2.6$ in control; $p<0.7 ; n=13$ ).

\section{Potentiation of synaptic transmission by NGF is mediated through Trk receptors}

Having determined that TrkA is predominantly expressed on the sympathetic neurons in the co-cultures, we tested whether the acute effects of NGF on neurotransmission were mediated through these receptors. Neuron-myocyte co-cultures were treated with NGF in the presence of $200 \mathrm{~nm} \mathrm{K252a}$ (Kase et al., 1986), a bacterial alkaloid protein kinase inhibitor. At nanomolar concentrations, K252a selectively blocks the tyrosine kinase activity of Trk receptors with little or no effect on receptor tyrosine kinases outside of this family (Nye et al., 1992; Tapley et al., 1992). In the presence of K252a alone, a myocyte showed a normal small elevation in beats per minute in response to stimulation of a connected neuron (Fig. 6A). However, in the presence of K252a, NGF did not potentiate the myocyte response to neuronal stimulation. In fact, under these conditions, NGF acted to suppress the increase in myocyte beat rate during neuronal stimulation, suggesting NGF-mediated inhibition of synaptic transmission in the presence of K252a. Figure $6 B$ shows the pooled data for these experiments. The average increase in myocyte beat rate in $\mathrm{K} 252 \mathrm{a}$ was $7.68 \pm 1.95$; the average change in $\mathrm{K} 252 \mathrm{a}+\mathrm{NGF}$ was $-1.46 \pm 3.1(n=5$; K252a + NGF significantly different from K252a alone; $p<0.05$ ). To test the possibility that $\mathrm{K} 252 \mathrm{a}$ alone had a progressive effect on myocyte beat rate during repeated neuronal stimulations, we stimulated neurons multiple times in the presence of K252a and in the absence of NGF. We found that K252a alone did not have a significant effect on myocyte beat rate after repeated stimulations, demonstrating a specific action of NGF in these cultures (data not shown). Likewise, in the absence of neuronal stimulation, the 


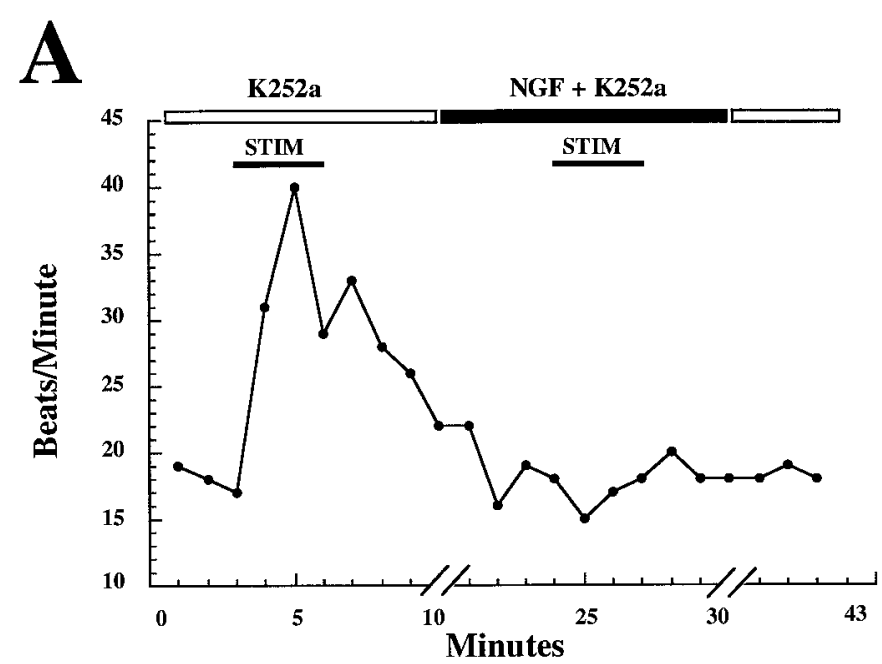

B

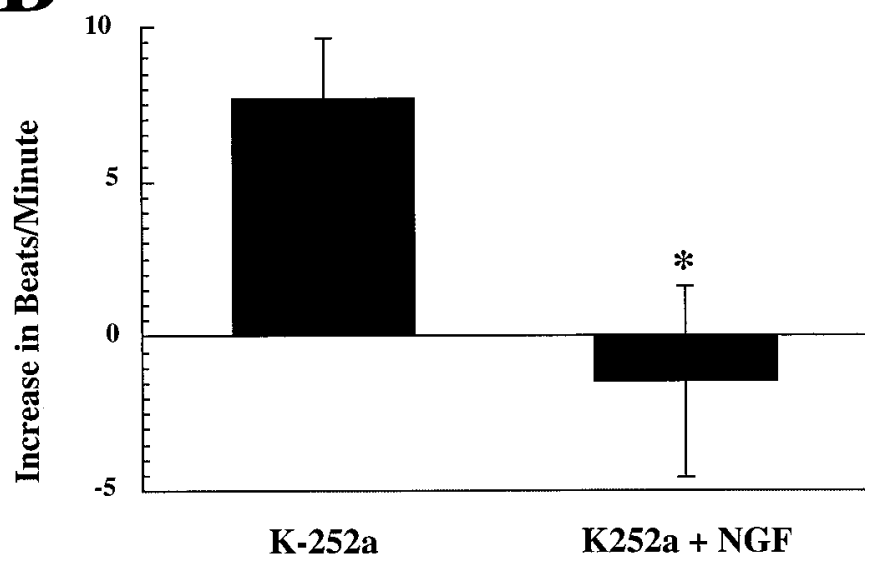

Figure 6. Effects of K252a. A, The kinase inhibitor K252a blocks potentiation and leads to inhibition of synaptic transmission by NGF. In the presence of $200 \mathrm{~nm} \mathrm{K252a}$ alone, a myocyte showed a normal small elevation in beats per minute in response to stimulation of a connected neuron. However, in the presence of K252a, NGF did not potentiate, and led to a decrease in, the myocyte response to neuronal stimulation. The breaks in the $x$-axis indicate that myocyte beat rate was not counted during these perfusion periods (10 min for initial perfusion of NGF, $10 \mathrm{~min}$ for washout). $B$, In K252a, NGF reduces synaptic transmission. Averaged, pooled data. On average, in the presence of K252a, NGF induces a significant decrease in the responses of myocytes to neuronal stimulation $(p<0.05$; paired Student's $t$ test; $n=5)$. Error bars represent SEM.

addition of NGF alone did not alter the baseline rate of myocyte beating in the presence of K252a.

\section{Effects of NGF during synapse formation}

Our experiments demonstrate that NGF, acting via Trk receptors, acutely potentiates synaptic transmission between sympathetic neurons and cardiac myocytes. To determine whether NGF also has long-term effects on synaptic transmission, we grew cocultures in two different concentrations of NGF, both of which support neuronal survival, and measured the effect on synaptic transmission. In this experiment, in contrast to the earlier experiments described, we examined data from all neuron-myocyte pairs, not just those that were found to be synaptically connected by our criterion of four beats/min. This approach permitted us to detect changes resulting from an NGF-mediated change in either synapse number or synaptic strength. This approach also resulted

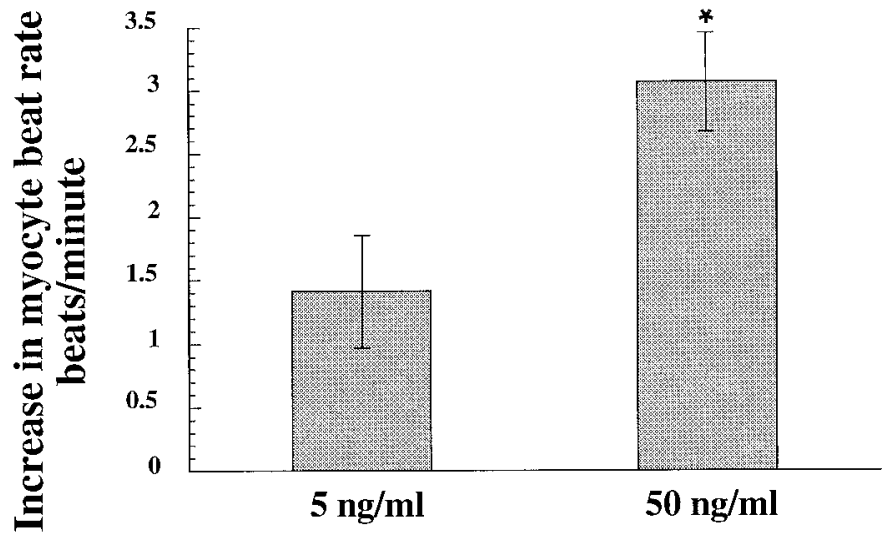

\section{Concentration NGF in growth medium}

Figure 7. Effect of NGF concentration in growth medium on response of myocytes to neuronal stimulation. Response of myocytes to neuronal stimulation in control medium was greater in cultures grown in $50 \mathrm{ng} / \mathrm{ml}$ NGF than in cultures grown in $5 \mathrm{ng} / \mathrm{ml}$. Neuron-myocyte co-cultures were grown for $3 \mathrm{~d}$ in 5 or $50 \mathrm{ng} / \mathrm{ml} \mathrm{NGF}$. Note that $5 \mathrm{ng} / \mathrm{ml}$ was sufficient to support full survival of sympathetic neurons in these cultures (Fig. 3). Neuron-myocyte pairs that had a visible process connecting the neuron and the myocyte were analyzed. After complete washout of growth medium, myocyte beat rate was counted before and during neuronal stimulation, and the change in beat rate during neuronal stimulation was calculated. Grown in $50 \mathrm{ng} / \mathrm{ml}$ NGF significantly different from grown in $5 \mathrm{ng} / \mathrm{ml} \mathrm{NGF}$ : unpaired Student's $t$ test, $p<0.03 ; n=135$ grown in 50 $\mathrm{ng} / \mathrm{ml} \mathrm{NGF}$ and $n=46$ grown in $5 \mathrm{ng} / \mathrm{ml} \mathrm{NGF}$.

in an assessment of both synaptically connected and unconnected pairs, producing a lower average increase in myocyte beat rate than in the other experiments described. Neurons and myocytes were co-cultured in the presence of 5 or $50 \mathrm{ng} / \mathrm{ml} \mathrm{NGF}$ for $3 \mathrm{~d}$, and for every neuron identified as having a physical process connecting it to a myocyte, the change in myocyte beat rate during neuronal stimulation in control solution was analyzed. We found that the average response of myocytes to neuronal stimulation was greater in cultures grown in $50 \mathrm{ng} / \mathrm{ml} \mathrm{NGF}$ than in cultures grown in $5 \mathrm{ng} / \mathrm{ml}$ (Fig. 7). In dishes grown in $5 \mathrm{ng} / \mathrm{ml}$ $\mathrm{NGF}$, the average myocyte response to neuronal stimulation was $1.4 \pm 0.4$ beats $/ \mathrm{min}$, whereas in dishes grown at $50 \mathrm{ng} / \mathrm{ml} \mathrm{NGF}$, the average response approximately doubled to $3.0 \pm 0.5$ beats/ $\min (50 \mathrm{ng} / \mathrm{ml}$ significantly different from $5 \mathrm{ng} / \mathrm{ml}$; unpaired Student's $t$ test; $p<0.03 ; n=135$ grown in $50 \mathrm{ng} / \mathrm{ml}$ and $n=46$ grown in $5 \mathrm{ng} / \mathrm{ml}$ ). This result cannot be accounted for by residual acute potentiation of cultures grown at $50 \mathrm{ng} / \mathrm{ml}$, because the acute effects of NGF on synaptic transmission are completely reversed within 15 min of NGF washout (Fig. 2) (S. T. Lockhart, unpublished data). In these experiments NGF was washed from the culture dish by perfusing with control solution for a minimum of $30 \mathrm{~min}$.

This difference in the average response to neuronal stimulation in cultures grown at different NGF concentrations could be attributable to either a change in the number of synaptic connections formed or a difference in the strength of individual synapses, or both. Using our connection criterion of four beats/min, we found that the connection probability (defined as the number of connected pairs divided by the total number of pairs tested, multiplied by 100) was lower in cultures grown at $5 \mathrm{ng} / \mathrm{ml} \mathrm{NGF}$ than in cultures grown at $50 \mathrm{ng} / \mathrm{ml}$ (22\% and $37 \%$, respectively). This may reflect a real difference in the number of connections formed, or it may reflect a change in synapse strength that 
reduced the number of pairs detectable by our connection criterion for cultures grown in $5 \mathrm{ng} / \mathrm{ml} \mathrm{NGF}$.

\section{DISCUSSION}

The survival effects of NGF on sympathetic neurons are critical in the establishment of sympathetic connections to the heart. However, the role of NGF as a modulator of synaptic activity at these synapses has not been examined previously. Neurotrophins have been shown to affect synaptic transmission at central and Xenopus neuromuscular synapses (Lohof et al., 1993; Kim et al., 1994; Kang and Schuman, 1995; Stoop and Poo, 1996). We have now demonstrated that NGF potentiates synaptic transmission between autonomic neurons and cardiac myocytes and influences the strength or number of synapses as they develop. Because NGF is produced by cardiac tissue (Korsching and Thoenen, 1988; Clegg et al., 1989), our results suggest that target-derived factors play a role in controlling the level of sympathetic input to the heart. Heart rate depends on the strength of the sympathetic synapses onto cardiac tissue; thus, our studies suggest that NGF is a modulator of cardiac function.

The modulation of sympathetic synapses by NGF suggests a broad and general role for neurotrophins in nervous system function. The central and neuromuscular synapses at which neurotrophins have been demonstrated to influence synaptic transmission have several characteristics in common. These synapses signal via fast synaptic transmission in which release of neurotransmitter from the presynaptic terminal results in the rapid opening of ion channels in the postsynaptic membrane (Lohof et al., 1993; Kang and Schuman, 1995). In contrast, noradrenergic sympathetic synapses produce a slow, second messenger-coupled postsynaptic response (Hartzell, 1981). Noradrenergic sympathetic synapses onto muscle cells are also characterized by distinct structural properties, including the absence of morphologically distinguishable active zones and variable, sometimes large distances (100-300 $\mathrm{nm}$ ) between the pre- and postsynaptic cells (Landis, 1976; Buckley and Landis, 1983; Kobayashi et al., 1984; Kitajiri et al., 1993). The fact that NGF modulates synaptic transmission through sympathetic synapses in a manner similar to that of neurotrophins at classical synapses in the brain and at the neuromuscular junction indicates that neurotrophins have widespread effects on synaptic function.

\section{Presynaptic effects of NGF}

At Xenopus neuromuscular synapses, NT-3 and BDNF lead to an increase in the frequency but not the amplitude of spontaneous synaptic currents, suggesting a presynaptic mechanism for neurotrophin action (Lohof et al., 1993). In the hippocampus, evidence exists for both pre- and postsynaptic effects of neurotrophins (Kang and Schuman, 1995; Levine et al., 1995; Tanaka et al., 1997). Our experiments demonstrate that TrkA is predominantly expressed on the sympathetic neurons in the neuronmyocyte co-culture, consistent with a presynaptic mechanism for NGF action in this system. Functional assays of myocyte response to NE indicate that NGF does not alter the postsynaptic response to neurotransmitter, further arguing for a presynaptic effect on transmitter release.

\section{Different dose-responses for NGF-mediated neuronal survival and synaptic potentiation}

One of the interesting aspects of the cardiac-sympathetic system is a potential role for NGF in regulating heart beat rate under conditions of sympathetic excitation. In neuron-myocyte cocultures, sympathetic neuronal survival is supported at low levels of NGF, whereas potentiation of synaptic transmission requires as much as 10-fold higher levels of NGF. This raises the possibility that NGF acts selectively on individual neurons to modulate cardiac function while more generally supporting neuronal survival. Because there may be local increases in NGF levels or in TrkA expression at neuron-myocyte synapses, the difference in dose dependence for the survival and modulatory effects of NGF may allow changes in NGF levels or NGF response to modulate synaptic function without impacting on neuronal survival. A role for such divergent effects of neurotrophins in the sympathetic lineage is supported by a number of observations in which neuronal survival requires a lower concentration of NGF than the regulation of molecules required for the mature neuronal phenotype. In primary cultures of rat sympathetic neurons, the level of NGF required to support neuronal survival was 2- to 10 -fold lower than the level needed to induce increased production of catecholamines (Chun and Patterson, 1977; Zurn and Mudry, 1986). In independent studies, $10 \mathrm{ng} / \mathrm{ml} \mathrm{NGF}$ was sufficient to support the survival of neonatal rat sympathetic neurons, whereas a maximal increase in tyrosine hydroxylase $(\mathrm{TH}) \mathrm{mRNA}, \mathrm{TH}$ activity, or process outgrowth required 100-200 ng/ml NGF (Hefti et al., 1982; Ma et al., 1992). These concentrations are comparable to the differences we have observed between the concentration of NGF required for survival (fully supported at 5 $\mathrm{ng} / \mathrm{ml})$ and synaptic potentiation $(50 \mathrm{ng} / \mathrm{ml})$, and they suggest that in general the modulation of molecules required for mature neuronal functions takes place at higher ranges of NGF.

\section{Trk receptors mediate the potentiation of synaptic transmission by NGF}

What are the potential mediators of NGF-dependent synaptic modulation in sympathetic neurons? Because TrkA is highly expressed on sympathetic neurons, it was likely that this receptor mediated the potentiation of synaptic transmission by NGF. We therefore predicted that the use of K252a to inhibit Trk signaling would prevent the potentiation of synaptic transmission by NGF. We found that K252a did abolish NGF-mediated synaptic potentiation. In fact, K252a led to an NGF-dependent depression in synaptic transmission (see text below).

K252a blocks signal transduction through all of the Trk receptors but has little or no effect on the tyrosine phosphorylation activity of other classes of receptor tyrosine kinases (Nye et al., 1992; Tapley et al., 1992). Thus, our experiments do not preclude the possibility that potentiation of sympathetic synapses is mediated through a Trk receptor other than TrkA. TrkC is expressed on sympathetic neurons, and these neurons have a survival response to NT-3 (Birren et al., 1993; DiCicco-Bloom et al., 1993; Zhou and Rush, 1995). However, it has recently been suggested that the TrkC expressed on these cells is nonfunctional and that NT-3 responsiveness is mediated through an alternative receptor (Dechant et al., 1997; Wyatt et al., 1997). Given the high level of TrkA expression in the neurons in our cultures, the most likely candidate receptor for NGF-mediated synaptic potentiation is TrkA.

The observation that in the absence of Trk signaling NGF decreases the level of synaptic transmission at sympathetic synapses suggests the presence of a second, non-Trk-mediated signal transduction pathway for NGF in this system. An interesting property of this putative second pathway is that it mediates an opposite biological response from the synaptic potentiation mediated through Trk receptors. One candidate for a second receptor for NGF in these cells is p75, the low-affinity neurotrophin receptor (Johnson et al., 1986; Radeke et al., 1987). p75 binds all 
of the neurotrophins with low affinity and modulates signal transduction through TrkA (Hantzopoulos et al., 1994; Verdi et al., 1994a). In addition, an independent signal transduction pathway involving the release of ceramide as a second messenger has been reported recently (Dobrowsky et al., 1994). p75 is expressed on developing sympathetic neurons (Verdi and Anderson, 1994; Wyatt and Davies, 1995), and our preliminary data demonstrate p75 mRNA expression in both neurons and myocytes in coculture (Lockhart, unpublished data). In the presence of TrkA, p75-mediated responses may be downregulated (Dobrowsky et al., 1995), but there is also evidence that the survival effects of NGF in the peripheral nervous system may be developmentally regulated by alterations in the relative levels of TrkA and p75 (Barrett and Bartlett, 1994; Ryden et al., 1997). Our results raise the possibility that in addition to mediating cell death and survival pathways, p75 may act to balance the level of synaptic transmission in the sympathetic nervous system.

\section{NGF and the formation of synaptic connections}

The level of NGF in a target tissue determines the extent of innervation by sympathetic neurons (Korsching and Thoenen, 1983; Shelton and Reichardt, 1984). Overexpression of NGF in the pancreas, heart, or skin of transgenic mice leads to sympathetic hyperinnervation of pancreatic islets, heart, or skin and lymphoid organs, respectively (Edwards et al., 1989; Albers et al., 1994; Carlson et al., 1995; Hassankhani et al., 1995). The relationship between NGF and the level of innervation may be caused by multiple factors. Target-derived NGF supports the survival of sympathetic neurons (Levi-Montalcini and Angeletti, 1963; Chun and Patterson, 1977), increasing the number of neurons available for innervation. Furthermore, NGF leads to an increase in the size of sympathetic dendritic arbors (Purves et al., 1988; Snider, 1988) and acts directly at the distal tips of sympathetic processes to promote the growth and structure of neurites (Campenot, 1982a,b). These studies suggest that NGF may enhance the number of synapses that form on sympathetic targets, but this possibility has not been tested physiologically. We took advantage of the observation that neuronal survival was fully supported by 5 $\mathrm{ng} / \mathrm{ml} \mathrm{NGF}$ in the neuron-myocyte co-cultures to investigate this possibility. We examined neuron-myocyte pairs that had a neuronal process physically connecting the neuron to the myocyte and found that co-cultures grown in $50 \mathrm{ng} / \mathrm{ml} \mathrm{NGF}$ had a higher average increase in myocyte beat rate during neuronal stimulation than did co-cultures grown in $5 \mathrm{ng} / \mathrm{ml}$. Therefore, in addition to its rapidly reversible effects on synaptic transmission, NGF leads to long-term changes in synaptic transmission at sympathetic synapses.

Two different models could account for the enhanced connectivity observed in cells cultured in high levels of NGF. One is that the level of NGF in the culture determines the number of synapses that form. This model would fit with studies demonstrating an increased level of sympathetic innervation of target tissues in transgenic mice that overexpress NGF (Edwards et al., 1989; Albers et al., 1994; Carlson et al., 1995; Hassankhani et al., 1995). NGF is known to enhance the growth and maintenance of sympathetic neuronal processes in vivo (Purves et al., 1988; Snider, 1988) and in vitro (Campenot, 1982a,b). Thus, an increase in the number of synapses could reflect an effect of NGF on process outgrowth, resulting in increased numbers of varicosities in cultures grown at high NGF concentrations.

A second possibility is that NGF does not alter the number of synapses but influences the strength of the synapses that form.
This appears to be the case at Xenopus neuromuscular synapses where neurotrophins potentiate the maturation of developing synapses (Wang et al., 1995). Sympathetic neurons respond to NGF by increasing the expression or activity (or both) of a number of molecules that could affect synaptic transmission at sympathetic neurons. These include tyrosine hydroxylase (Thoenen et al., 1974; Otten et al., 1977; Max et al., 1978; Raynaud et al., 1988), the rate-limiting enzyme for the synthesis of NE, neuropeptides (Hayashi et al., 1984; Zigmond and Sun, 1997), and catecholamines (Chun and Patterson, 1977; Zurn and Mudry, 1986). Thus, the increase in synaptic transmission we observed in neuron-myocyte pairs cultured in $50 \mathrm{ng} / \mathrm{ml} \mathrm{NGF}$ could be a consequence of altered levels of neurotransmitter at the presynaptic terminals. It is important to note that the two models proposed for long-term effects of NGF at sympathetic synapses, an increase in synapse number and an increase in synaptic strength, are not mutually exclusive.

NGF has long been known as a survival factor for sympathetic neurons. The level of NGF expression in targets of sympathetic innervation has been linked to the extent of target innervation (Korsching and Thoenen, 1983; Shelton and Reichardt, 1984). That the level of NGF and sympathetic innervation can have consequences for cardiovascular function is suggested by studies linking NGF production to hypertension in spontaneously hypertensive rats (Zettler and Rush, 1993). Here we have shown that NGF acts in the sympathetic system to acutely potentiate synaptic transmission between sympathetic neurons and cardiac myocytes and to influence the development of these synaptic connections. These results suggest a novel role for NGF as a modulator of cardiac function.

\section{REFERENCES}

Albers KM, Wright DE, Davis BM (1994) Overexpression of nerve growth factor in epidermis of transgenic mice causes hypertrophy of the peripheral nervous system. J Neurosci 14:1422-1432.

Armour JA, Ardell JL (1994) Neurocardiology. New York: Oxford UP.

Barrett GL, Bartlett PF (1994) The p75 nerve growth factor receptor mediates survival or death depending on the stage of sensory neuron development. Proc Natl Acad Sci USA 91:6501-6505.

Birren SJ, Lo LC, Anderson DJ (1993) Sympathetic neurons undergo a developmental switch in trophic dependence. Development 119:597-610.

Buckley KM, Landis SC (1983) Morphological studies of synapses and varicosities in dissociated cell cultures of sympathetic neurons. J Neurocytol 12:67-92.

Campenot RB (1982a) Development of sympathetic neurons in compartmentalized cultures. I. Local control of neurite growth by nerve growth factor. Dev Biol 93:1-12.

Campenot RB (1982b) Development of sympathetic neurons in compartmentalized cultures. II. Local control of neurite survival by nerve growth factor. Dev Biol 93:13-21.

Cannon WB (1929) Bodily changes in pain, hunger, fear and rage. New York: Appleton.

Carlson SL, Albers KM, Beiting DJ, Parish M, Conner JM, Davis BM (1995) NGF modulates sympathetic innervation of lymphoid tissue. J Neurosci 15:5892-5899.

Chomszynski P, Sacchi N (1987) Single-step method of RNA isolation by acid guanidinium thiocyanate-phenol-chloroform extraction. Anal Biochem 162:156-159.

Chun LLY, Patterson PH (1977) Role of nerve growth factor in the development of rat sympathetic neurons in vitro. $\mathrm{J}$ Cell Biol 75:694-704.

Clegg DO, Large TH, Bodary SC, Reichart LF (1989) Regulation of nerve growth factor mRNA levels in developing rat heart ventricle is not altered by sympathectomy. Dev Biol 134:30-37.

Conforti L, Tohse N, Sperelakis N (1991) Influence of sympathetic innervation on the membrane electrical properties of neonatal rat cardiomyocytes in culture. J Dev Physiol 15:237-246. 
Cowan WM, Fawcett JW, O'Leary DDM, Stanfield BB (1984) Regressive events in neurogenesis. Science 225:1258-1265.

Davies AM, Bandtlow C, Heumann R, Korsching S, Rohrer H, Thoenen $\mathrm{H}$ (1987) The site and timing of nerve growth factor (NGF) synthesis in developing skin in relation to its innervation by sensory neurons and their expression of NGF receptors. Nature 326:353-358.

Dechant G, Tsoulfas P, Parada LF, Barde YA (1997) The neurotrophin receptor p75 binds neurotrophin-3 on sympathetic neurons with high affinity and specificity. J Neurosci 17:5281-5287.

DiCicco-Bloom E, Friedman WJ, Black IB (1993) NT-3 stimulates sympathetic neuroblast proliferation by promoting precursor survival. Neuron 11:1101-1111.

Dobrowsky RT, Werner MH, Castellino AM, Chao MV, Hannun YA (1994) Activation of the sphingomyelin cycle through the low affinity neurotrophin receptor. Science 265:1596-1599.

Dobrowsky RT, Jenkins GM, Hannun YA (1995) Neurotrophins induce sphingomyelin hydrolysis. J Biol Chem 270:22135-22142.

Edwards RH, Rutter WJ, Hanahan D (1989) Directed expression of NGF to pancreatic $\beta$ cells in transgenic mice leads to selective hyperinnervation of the islets. Cell 58:161-170.

Eide FF, Lowenstein D, Reichardt LF (1993) Neurotrophins and their receptors. Current concepts and implications for neurologic disease. Exp Neurol 121:200-214.

Figurov A, Pozzo-Miller LD, Olafsson P, Wang T, Lu B (1996) Regulation of synaptic responses to high-frequency stimulation and LTP by neurotrophins in the hippocampus. Nature 381:706-709.

Furshpan EJ, MacLeish PR, O'Lague PH, Potter DD (1976) Chemical transmission between rat sympathetic neurons and cardiac myocytes developing in microcultures: evidence for cholinergic, adrenergic, and dual-function neurons. Proc Natl Acad Sci USA 73:4225-4229.

Furshpan EJ, Landis SC, Matsumoto SG, Potter DD (1986) Synaptic functions in rat sympathetic neurons in microcultures. I. Secretion of norepinephrine and acetylcholine. J Neurosci 6:1061-1079.

Hantzopoulos PA, Suri C, Glass DJ, Goldfarb MP, Yancopoulos GD (1994) The low affinity NGF receptor, p75, can collaborate with each of the trks to potentiate functional responses to the neurotrophins. Neuron 13:187-201.

Hartzell HC (1981) Mechanisms of slow postsynaptic potentials. Nature 291:539-544.

Hassankhani A, Steinhelper ME, Soonpaa MH, Katz EB, Taylor DA, Andrade-Rozental A, Factor SM, Steinberg JJ, Field LJ, Federoff HJ (1995) Overexpression of NGF within the heart of transgenic mice causes hyperinnervation, cardiac enlargement, and hyperplasia of ectopic cells. Dev Biol 169:309-321.

Hawrot E, Patterson PH (1979) Long-term culture of dissociated sympathetic neurons. Methods Enzymol 58:574-583.

Hayashi M, Edgar D, Thoenen H (1984) Nerve growth factor changes the relative levels of neuropeptides in developing sensory and sympathetic ganglia of the chick embryo. Dev Biol 108:49-55.

Hefti F, Gnahn H, Schwab ME, Thoenen H (1982) Induction of tyrosine hydroxylase by nerve growth factor and by elevated $\mathrm{K}^{+}$concentration in cultures of dissociated sympathetic neurons. J Neurosci 2:1554-1566.

Johnson D, Lanahan A, Buck CR, Sehgal A, Morgan C, Mercer E, Bothwell M, Chao MV (1986) Expression and structure of the human NGF receptor. Cell 47:545-554.

Johnson Jr EM, Taniuchi M, DiStefano PS (1988) Expression and possible function of nerve growth factor receptors on Schwann cells. Trends Neurosci 11:299-304.

Kang H, Schuman EM (1995) Long-lasting neurotrophin-induced enhancement of synaptic transmission in the adult hippocampus. Science 267:1658-1662.

Kaplan DR, Hempstead BL, Martin-Zanca D, Chao MV, Parada LF (1991) The trk proto-oncogene product: a signal transducing receptor for nerve growth factor. Science 252:554-558.

Kase H, Iwahashi K, Nakanishi S, Matsuda Y, Yamada K, Takahashi M, Murakata C, Sato A, Kaneko M (1986) K-252a compounds, novel and potent inhibitors of protein kinase $\mathrm{C}$ and cyclic nucleotide-dependent protein kinases. Biochem Biophys Res Commun 142:436-440.

Kim HG, Wang T, Olafsson P, Lu B (1994) Neurotrophin 3 potentiates neuronal activity and inhibits gamma-aminobutyrate synaptic transmission in cortical neurons. Proc Natl Acad Sci USA 91:12341-12345.

Kitajiri M, Kubo N, Tomoda K, Maeda N, Yamashita T, Kumazawa T (1993) Sympathetic nerve disturbance and fine structure of adrenergic nerve terminals in nasal mucosa after experimentally-induced nasal hypersensitivity. Acta Otolaryngol (Stockh) 503:47-50.
Klein R, Jing S, Nanduri V, O’Rourke E, Barbacid M (1991) The trk proto-oncogene encodes a receptor for nerve growth factor. Cell 65:189-197.

Knipper M, da Penha Berzaghi M, Blochl A, Breer H, Thoenen H, Lindholm D (1994) Positive feedback between acetylcholine and the neurotrophins nerve growth factor and brain-derived neurotrophic factor in the rat hippocampus. Eur J Neurosci 6:668-671.

Kobayashi T, Matsumoto Y, Tsukagoshi H, Kayanuma K, Hori S (1984) Fine structure of the synaptic endings between sympathetic axons and skeletal muscle cells and of the varicosities in the bundles of neurites in tissue culture. Exp Neurol 85:187-201.

Korsching S, Thoenen H (1983) Nerve growth factor in sympathetic ganglia and corresponding target organs of the rat: correlation with density of sympathetic innervation. Proc Natl Acad Sci USA 80:3513-3516.

Korsching S, Thoenen H (1988) Developmental changes of nerve growth factor levels in sympathetic ganglia and their target organs. Dev Biol 126:40-46.

Korte M, Carroll P, Wolf E, Brem G, Thoenen H, Bonhoeffer T (1995) Hippocampal long-term potentiation is impaired in mice lacking brainderived neurotrophic factor. Proc Natl Acad Sci USA 92:8856-8860.

Landis SC (1976) Rat sympathetic neurons and cardiac myocytes developing in microcultures: correlation of the fine structure of endings with neurotransmitter function in single neurons. Proc Natl Acad Sci USA 73:4220-4224.

Levi-Montalcini R (1987) The nerve growth factor 35 years later. Science 237:1154-1162.

Levi-Montalcini R, Angeletti PU (1963) Essential role of the nerve growth factor in the survival and maintenance of dissociated sensory and sympathetic embryonic nerve cells in vitro. Dev Biol 7:653-659.

Levi-Montalcini R, Angeletti PU (1968) Nerve growth factor. Physiol Rev 48:534-569.

Levi-Montalcini R, Booker B (1960) Destruction of the sympathetic ganglia in mammals by an antiserum to a nerve growth protein. Proc Natl Acad Sci USA 46:384-391.

Levine ES, Dreyfus CF, Black IB, Plummer MR (1995) Brain-derived neurotrophic factor rapidly enhances synaptic transmission in hippocampal neurons vial postsynaptic tyrosine kinase receptors. Proc Natl Acad Sci USA 92:8074-8077.

Lohof AM, Ip NY, Poo MM (1993) Potentiation of developing neuromuscular synapses by the neurotrophins NT-3 and BDNF. Nature 363:350-353.

Ma Y, Campenot RB, Miller FD (1992) Concentration-dependent regulation of neuronal gene expression by nerve growth factor. J Cell Biol 117:135-141.

Max SR, Rohrer H, Otten U, Thoenen H (1978) Nerve growth factormediated induction of tyrosine hydroxylase in rat superior cervical ganglia in vitro. J Biol Chem 253:8013-8015.

Nobin A, Baumgarten HG, Falck B, Ingemansson S, Moghimzadeh E, Rosengren E (1979) Organization of the sympathetic innervation in liver tissue from monkey and man. Cell Tissue Res 195:371-380.

Nye SH, Squinto SP, Glass DJ, Stitt TN, Hantzopoulos P, Macchi MJ, Lindsay NS, Ip NY, Yancopoulos GD (1992) K-252A and staurosporine selectively block autophosphorylation of neurotrophin receptors and neurotrophin-mediated responses. Mol Biol Cell 3:677-686.

Otten U, Schwab M, Gagnon C, Thoenen H (1977) Selective induction of tyrosine hydroxylase and dopamine $\beta$-hydroxylase by nerve growth factor: comparison between adrenal medulla and sympathetic ganglia of adult and newborn rats. Brain Res 133:291-303.

Purves D (1988) Body and brain: a trophic theory of neural connections. Cambridge, MA: Harvard UP.

Purves D, Snider WD, Voyvodic JT (1988) Trophic regulation of nerve cell morphology and innervation in the autonomic nervous system. Nature 336:123-128.

Radeke MJ, Misko TP, Hsu C, Herzenberg LA, Shooter EM (1987) Gene transfer and molecular cloning of the rat nerve growth factor receptor. Nature 325:593-597.

Raynaud B, Faucon-Biguet N, Vidal S, Mallet J, Weber MJ (1988) Regulation of neurotransmitter metabolic enzymes and tyrosine hydroxylase mRNA level by nerve growth factor in cultured sympathetic neurons. Development 102:361-368.

Rutherford LC, DeWan A, Lauer HM, Turrigiano GG (1997) Brainderived neurotrophic factor mediates the activity-dependent regulation of inhibition in neocortical cultures. J Neurosci 17:4527-4535.

Ryden M, Hempstead B, Ibanez CF (1997) Differential modulation of 
neuron survival during development by nerve growth factor binding to the p75 neurotrophin receptor. J Biol Chem 272:16322-16328.

Shelton DL, Reichardt LF (1984) Expression of the $\beta$ nerve growth factor gene correlates with the density of sympathetic innervation in effector organs. Proc Natl Acad Sci USA 81:7951-7955.

Snider WD (1988) Nerve growth factor enhances dendritic arborization of sympathetic ganglion cells in developing mammals. J Neurosci $8: 2628-2634$

Stoop R, Poo M (1996) Synaptic modulation by neurotrophic factors: differential and synergistic effects of brain-derived neurotrophic factor and ciliary neurotrophic factor. J Neurosci 16:3256-3264.

Takei N, Sosaoka K, Inoue K, Takahashi M, Endo Y, Hatanaka H (1997) Brain-derived neurotrophic factor increases the stimulation-evoked release of glutamate and the levels of exocytosis-associated proteins in cultured cortical neurons from embryonic rats. J Neurochem 68:370-375.

Tanaka T, Saito H, Matsuki N (1997) Inhibition of $\mathrm{GABA}_{\mathrm{A}}$ synaptic responses by brain-derived neurotrophic factor (BDNF) in rat hippocampus. J Neurosci 17:2959-2966.

Tapley P, Lamballe F, Barbacid M (1992) K252a is a selective inhibitor of the tyrosine protein kinase activity of the trk family of oncogenes and neurotrophin receptors. Oncogene 7:371-381.

Thoenen H, Angeletti PU, Levi-Montalcini R, Kettler R (1974) Selective induction by nerve growth factor of tyrosine hydroxylase and dopamine $\beta$ hydroxylase in rat superior cervical ganglion. Proc Natl Acad Sci USA 68:1598-1602.

Thoenen H, Barde Y-A (1980) Physiology of nerve growth factor. Physiol Rev 60:1284-1335.

Verdi JM, Anderson DJ (1994) Neurotrophins regulate sequential changes in neurotrophin receptor expression by sympathetic neuroblasts. Neuron 13:1359-1372.

Verdi JM, Birren SJ, Ibáñez CF, Persson H, Kaplan DR, Benedetti M, Chao MV, Anderson DJ (1994a) p75 ${ }^{\text {LNGFR }}$ regulates trk signal transduction and NGF-induced neuronal differentiation in MAH cells. Neuron 12:733-745.

Verdi JM, Yancopoulos GD, Ip NY, Anderson DJ (1994b) Expression of trk in MAH cells lacking the p75 low-affinity nerve growth factor receptor is sufficient to permit nerve growth factor-induced differentiation to postmitotic neurons. Proc Natl Acad Sci USA 91:3949-3953.

Wang T, Xie K, Lu B (1995) Neurotrophins promote maturation of developing neuromuscular synapses. J Neurosci 15:4796-4805.

Wyatt S, Davies AM (1995) Regulation of nerve growth factor receptor gene expression in sympathetic neurons during development. J Cell Biol 130:1435-1446.

Wyatt S, Pinon LG, Ernfors P, Davies AM (1997) Sympathetic neuron survival and TrkA expression in NT3-deficient mouse embryos. EMBO J 16:3225-3123.

Zettler C, Rush RA (1993) Elevated concentrations of nerve growth factor in heart and mesenteric arteries of spontaneously hypertensive rats. Brain Res 614:15-20.

Zhou XF, Rush R (1995) Sympathetic neurons in neonatal rats require endogenous neurotrophin-3 for survival. J Neurosci 15:6521-6530.

Zigmond RE, Sun Y (1997) Regulation of neuropeptide expression in sympathetic neurons. Paracrine and retrograde influences. Ann NY Acad Sci 814:181-197.

Zurn AD, Mudry F (1986) Conditions increasing the adrenergic properties of dissociated chick superior cervical ganglion neurons grown in long-term culture. Dev Biol 117:365-379. 